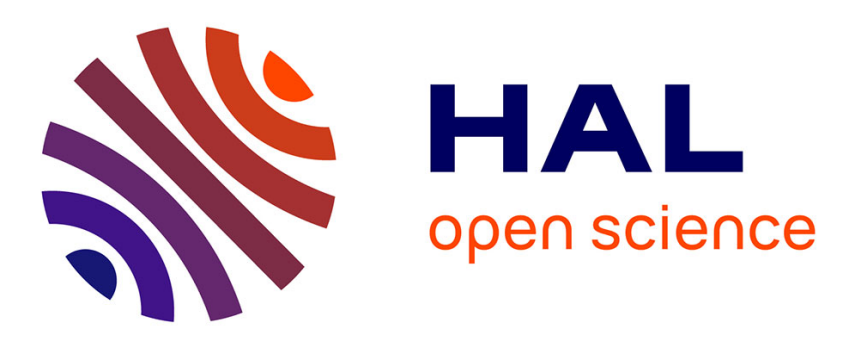

\title{
Thermal Modeling of a Spiral Planar Inductor
}

Rabia Melati, Melati Rabia, Hamid Azzedine, Adda Benattia Tekkouk

\section{To cite this version:}

Rabia Melati, Melati Rabia, Hamid Azzedine, Adda Benattia Tekkouk. Thermal Modeling of a Spiral Planar Inductor. Journal of Low Power Electronics, 2017, 13, pp.114 - 121. 10.1166/jolpe.2017.1474 . hal-03233685

\section{HAL Id: hal-03233685 \\ https://hal.science/hal-03233685}

Submitted on 25 May 2021

HAL is a multi-disciplinary open access archive for the deposit and dissemination of scientific research documents, whether they are published or not. The documents may come from teaching and research institutions in France or abroad, or from public or private research centers.
L'archive ouverte pluridisciplinaire HAL, est destinée au dépôt et à la diffusion de documents scientifiques de niveau recherche, publiés ou non, émanant des établissements d'enseignement et de recherche français ou étrangers, des laboratoires publics ou privés. 


\title{
Thermal Modeling of a Spiral Planar Inductor
}

\author{
Melati Rabia $^{{ }^{*}}$, Hamid Azzedine ${ }^{1}$, Adda Benattia Tekkouk ${ }^{2}$ \\ ${ }^{1}$ Department of Electrical Engineering, Faculty of Electrical Engineering \\ University of Science and Technology of Oran USTO $\underline{\text { mel_ati@hotmail.fr }}$, hamidazdean@yahoo.fr \\ ${ }^{2}$ Department of Physics, Faculty of Exact Sciences and Informatics \\ University of Mostaganem UMAB addatekkouk@yahoo.fr
}

Source: Journal of Low Power Electronics, Volume 13, Number 1, March 2017, pp. 114-121(8)

Publisher: American Scientific Publishers

DOI: https://doi.org/10.1166/jolpe.2017.1474 


\title{
Thermal Modeling of a Spiral Planar Inductor
}

\author{
Melati Rabia $^{1 *}$, Hamid Azzedine ${ }^{1}$, Adda Benattia Tekkouk ${ }^{2}$.
}

\begin{abstract}
In the literature, it is common practice to use well-known and particularly robust numerical methods, such as the finite difference method and the finite element method for calculating the temperature in electronic components or devices.

To calculate the operating temperature of a spiral planar inductor, we will adopt a method that is simpler to implement and gives equally reliable results. This method is based on the design of the thermal circuit of the inductor.

The design of the thermal circuit results from the decomposition of the inductor into volume elements $V i$ and the similarity between the thermal and electrical circuits.

By applying the nodal method, each volume defines a thermal sub-circuit. The assembly forms a complicated global circuit. This circuit is simplified into a " $\pi$ " thermal circuit.

The " $\pi$ " thermal circuit associated with the Fourier's law facilitates calculation of the temperatures in different areas of the inductor.

The obtained results are good and are validated by the simulation of heat flux. This simulation is performed with FEMLAB software.
\end{abstract}

Keywords - Spiral planar inductor - Thermal circuit - Integrated inductor - Thermal modelingHeat transfer-Thermal effect. 


\section{INTRODUCTION}

In microelectronics, the involvement of more and higher power dissipation on very restricted surfaces can cause considerable heating. Thus, the problems associated with the heat dissipation in the electronic systems are of great importance.

Thermal effects in power electronics systems can manifest in different ways, either by a drift of components temperature resulting in significant variations in the electrical performance, or by a rise in temperature which can cause welds connecting the components due to dimensional variations.

The nature of materials used in the manufacture of electronic components, in turn requires a working temperature limit, because a poorly managed operating temperature can lead to a change of state of materials, such as degaussing of magnetic materials, or the fusion of conductive materials. Therefore, to ensure the good operation and longevity of an electronic component, the operating temperature must be well controlled [1-6].

\section{PRESENTATION OF THE SPIRAL PLANAR INDUCTOR}

The micro-coil selected is a square planar spiral type, its geometrical parameters are respectively: the internal and external diameters $\boldsymbol{d}_{\text {in }}$ and $\boldsymbol{d}_{\text {out }}$, the number of turns $\boldsymbol{n}$, the inter-turn spacing $\boldsymbol{s}$, the width $\boldsymbol{w}$ and the thickness $\boldsymbol{t}$ of the conductor (figure 1).

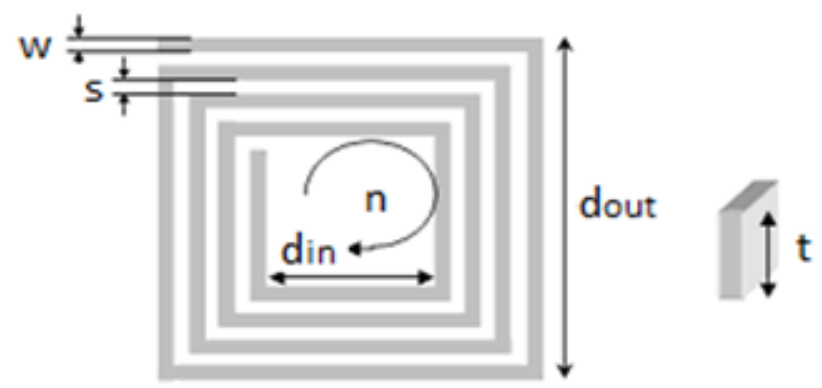

Figure1. Geometrical parameters of the square spiral planar inductor

The copper spiral is placed on a ferromagnetic core. The core is a parallelepiped block of thickness $h_{\text {mag }}$. This spiral is separated from the core by an insulating layer of silicon dioxide of thickness $t_{o x}$. The assembly is placed on a semiconductor substrate with $h_{s u b}$ thickness (figure2).

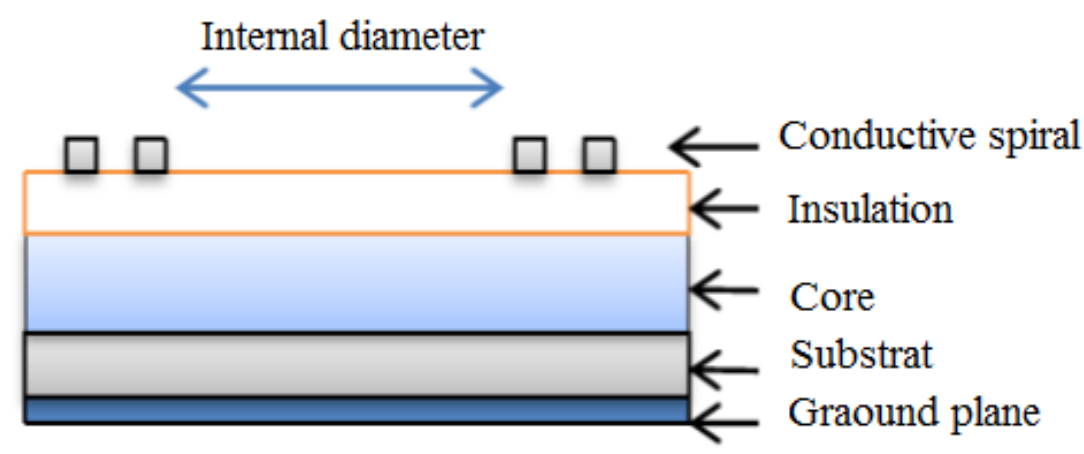

Figure 2. Cross section of the spiral planar inductor 
This inductor is dimensioned to be integrated into a buck DC / DC micro- converter (Figure3).

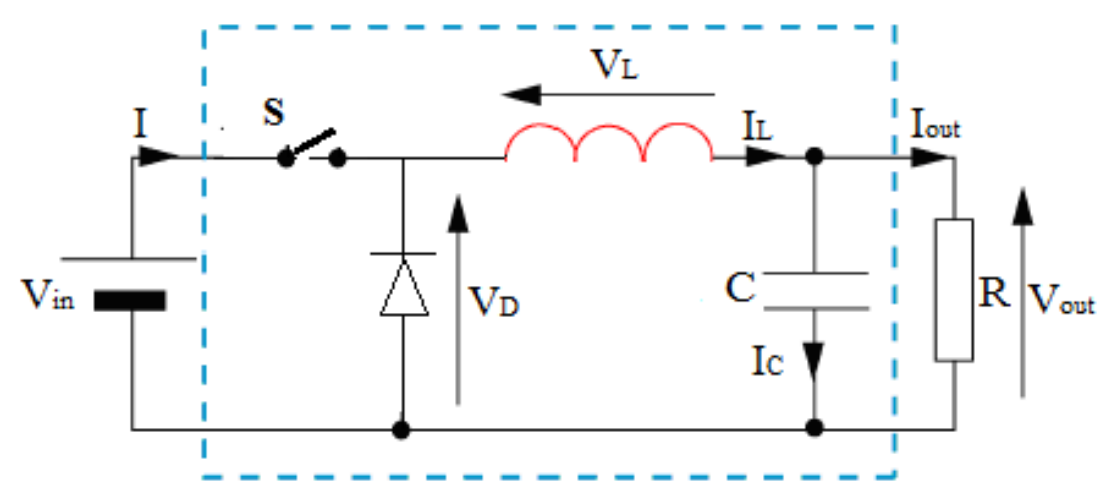

Figure 3. Schematic diagram of the buck converter

We choose the schedule of conditions according to:

Input voltage: $V_{\text {in }}=5 \mathrm{~V}$

Output voltage: $V_{\text {out }}=5 \mathrm{~V}$

Average output current: $I_{\text {out }}=0.38 \mathrm{~A}$

Maximal current: $I_{L \max }=0.6 \mathrm{~A}$

Operation frequency : $f=1.5 \mathrm{MHz}$.

The dimensioning of the inductor is performed with the dimensioning method presented by the authors in a previous works [7]. It should be noted that this dimensioning is performed so as to attenuate the skin effect considerably.

The planar inductor is traversed by a current of maximum value $I_{L \max }=0.6 \mathrm{~A}$ and minimum value $I_{\text {Lmin }}=0.16 \mathrm{~A}$. The calculated value of the inductance is $L=1.89 \mu \mathrm{H}$ [7].

The dimensioning results are summarized in Table I [7].

TABLE I

VALUES OF THE INDUCTOR GEOMETRICAL PARAMETERS

\begin{tabular}{lc}
\hline \hline Geometrical parameters & Values $(\boldsymbol{\mu m})$ \\
\hline \hline Number of turns : $\boldsymbol{n}$ & 2 \\
Average conductor length $: \boldsymbol{L}_{\text {avg }}$ & 4402,5 \\
Conductor width : $\boldsymbol{w}$ & 120 \\
Conductor thickness : $\boldsymbol{t}$ & 20 \\
Inter-turn spacing: $\boldsymbol{s}$ & 97,5 \\
External diameter of the spiral: $\boldsymbol{d}_{\text {out }}$ & 900 \\
Internal diameter of the spiral: $\boldsymbol{d}_{\text {in }}$ & 225 \\
The thickness of the core: $\boldsymbol{I}_{\text {Lmag }}$ & 640 \\
The thickness of the insulating layer: $\mathbf{t}_{\boldsymbol{o x}}$ & 60 \\
The thickness of the substrate: $\boldsymbol{h}_{\text {sub }}$ & 100 \\
\hline
\end{tabular}

Our objective is to calculate the operating temperature of the planar inductor using a simple and reliable method. To do this, we will first design the thermal circuit of the inductor. 


\section{THERMAL MODEL OF SPIRAL PLANAR INDUCTOR}

In the literature, generally, we use robust numerical methods, such as finite difference method and the finite element method to calculate the temperature in components or devices electronic [8]. In this paper, we will adopt a method that is simpler to implement and gives equally reliable results. This method is based on the design of the thermal circuit.

To design the thermal circuit of our spiral planar inductor, we propose an original approach, based on the nodal method [9] [10] [11]. This thermal circuit makes it possible to determine the operating temperature of our component.

\subsection{The nodal method}

The nodal method makes it possible to discretize the medium to be studied into elements of volumes $V_{i}$ assumed with an isothermal temperature $T_{i}$. Each volume $V_{i}$ is characterized by a thermal capacity $C_{i}$ and a heat source $P_{i}$. The gravity centres of the volumes $V_{i}$ called nodes are interconnected (Figure 4) [11] [12].
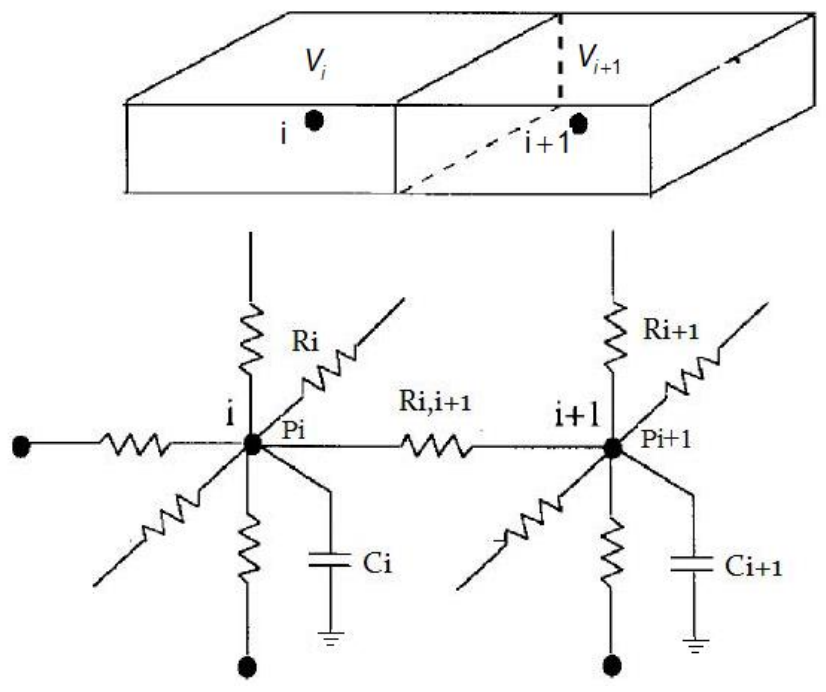

Figure 4. Three-dimensional mesh network

\subsection{Thermal model of the spiral planar inductor}

The main objective of the thermal modeling of the spiral planar inductor is to obtain a simple and reliable model allowing to determine its operating temperature. This temperature depends on Joule effect losses and iron losses. The Joule effect losses in the conductive spiral are the main source of heat.

\subsubsection{Simplifying assumptions}

The development of the thermal model of the inductor is based on the following simplifying assumptions:

- The dimensions of our inductor are very small (a few micro meters), and there is no fluid matter in the inductor, so the convective heat transfer is negligible.

- We assume that the heat transfer by conduction is unidirectional.

- The surfaces of the stacked layers are assumed to be very smooth, so the thermal capacities at the interfaces are negligible. 


\subsection{Design of the inductor thermal circuit}

To design the thermal circuit using the nodal method, we discretize our inductor into volume elements $V_{k}$. We first discretize the spiral into nine segments of sections $S_{k}(k=1, \ldots 9)$, and of volumes $V_{l, k}(k=1, \ldots 9)$. The gravity center of each volume $V_{l, k}$ is a node (Figure 5).

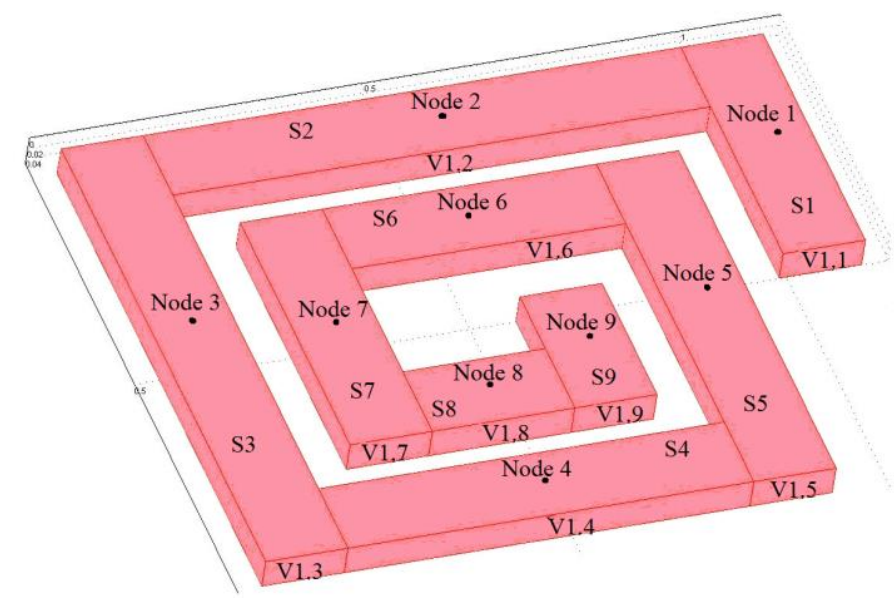

Figure 5. The different sections $S_{k}$ and different volumes $V_{l, k}$ of the spiral

The cross section of the inductor shows the different thermal resistances $R_{t h}$ and thermal capacities $C_{\text {thi }}(i=1, \ldots 3)$ and $C_{v i}(i=1, \ldots 5)$ associated with each node (Figure 6).

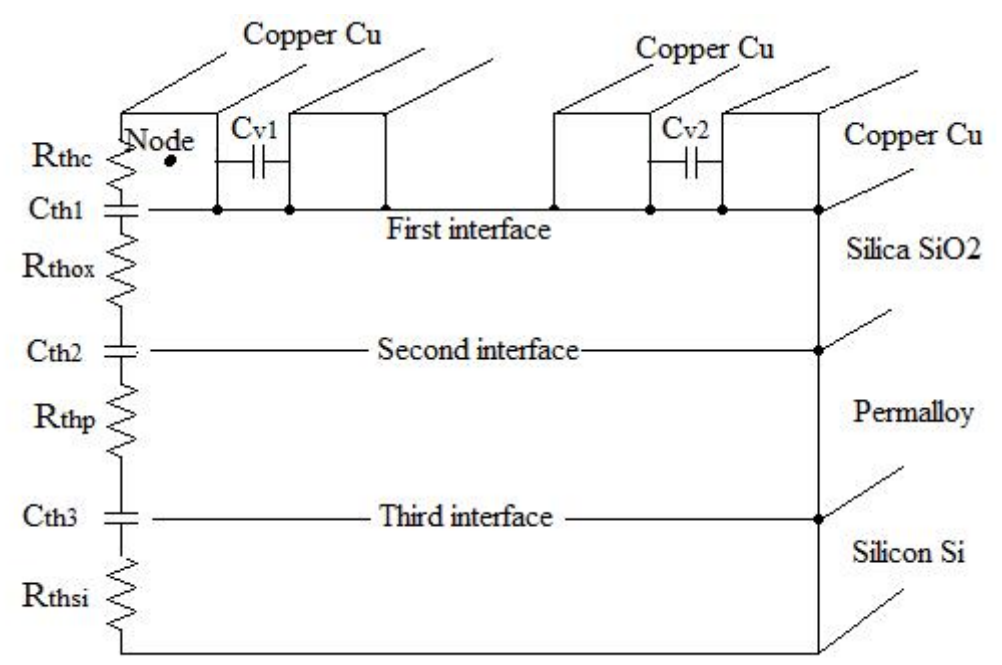

Figure 6. Cross section of the inductor, different thermal resistances and capacities associated with a node

Note that the overall volume of the conductive ribbon of the inductor is the main source of heat, and volumes $V_{l, k}(k=1, \ldots 9)$ are sub-sources of heat. In each volume, the heat is transferred to the three layers of materials stacked below. Applying the nodal method, we consider that the node of each volume $V_{l, k}$ (Figure7) is associated with a thermal sub-circuit (Figure 8) . 


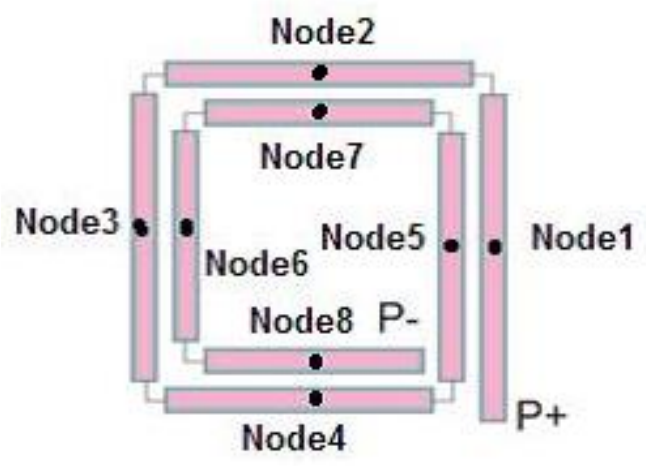

Figure 7. Discretization of the conductive ribbon into volumes associated with their nodes

The cross section of the inductor (Figure 6), the discretization of the conductive ribbon into volumes $V_{l, k}$ associated with their nodes (Figure 7) and the similarity between the electrical and thermal phenomena, allowed us to design an overall thermal model of the inductor (Figure 8).

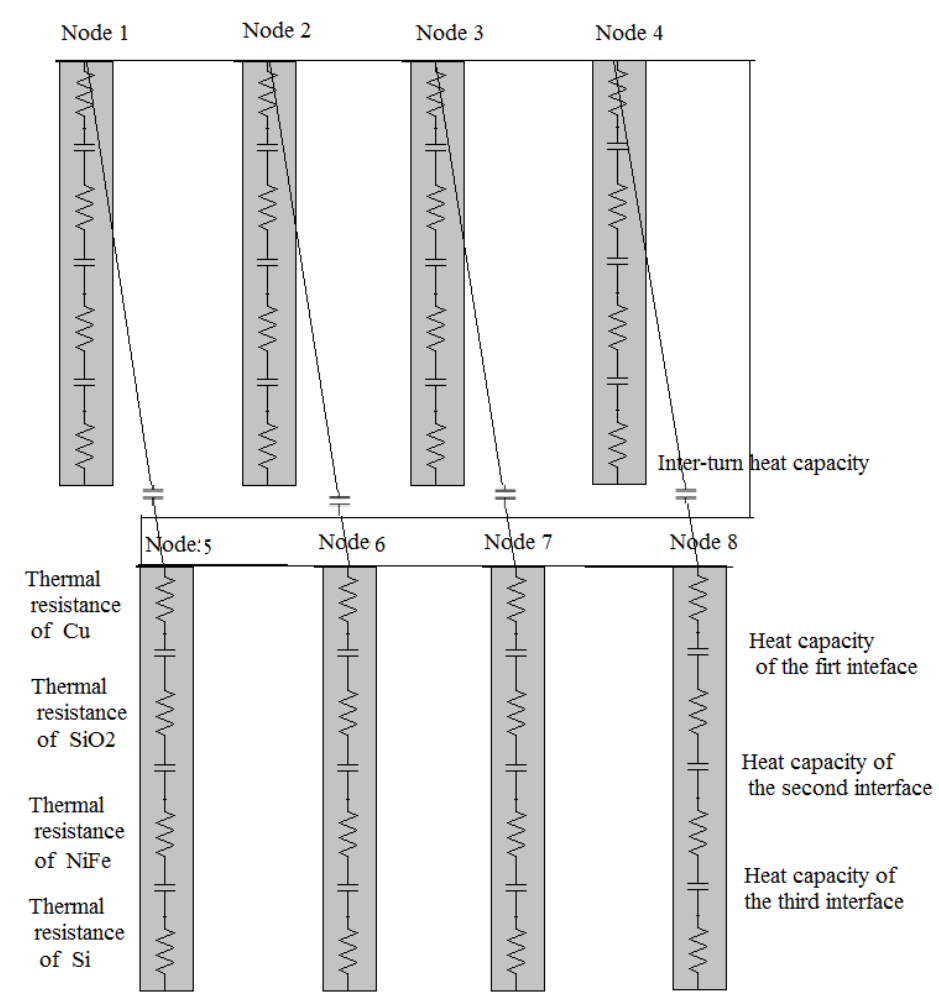

Figure 8. Overall thermal circuit of the inductor

The thermal sub-circuits in the first four nodes are then connected in series. It is the same for the sub-circuits of the last four nodes. The whole is modelled by a " $\pi$ " thermal circuit (Figure 9).

Thermal capacities between the segments must also be taken into account.

Note that the model considers just the thermal capacities between the adjacent parallel segments. This approximation is valid because the thermal capacities between the other segments are negligible. 


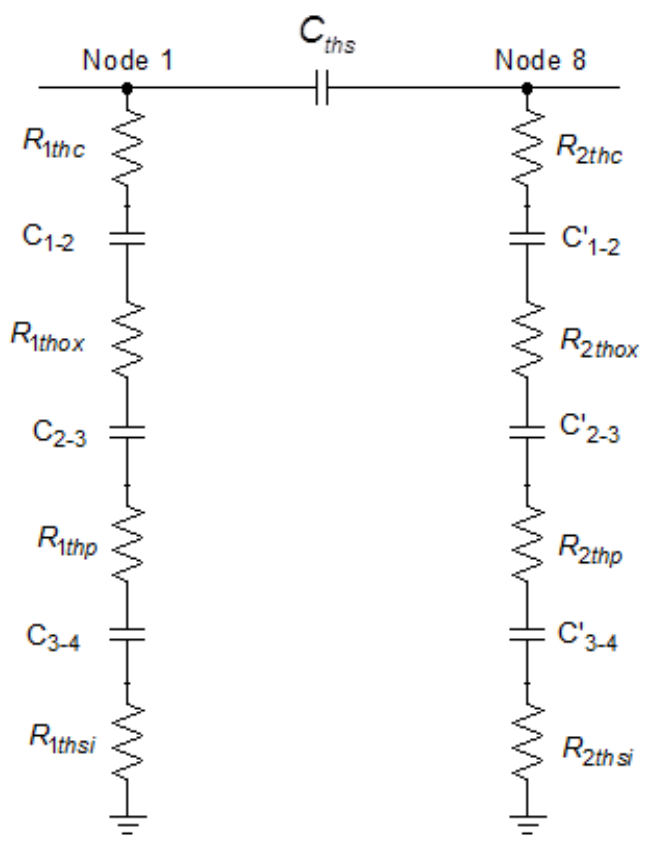

Figure 9. The " $\pi$ " Thermal circuit of the spiral planar inductor

$C_{t h s}$ is the equivalent thermal capacity of inter-turns thermal capacities.

$R_{\text {jthc }}, R_{\text {jthox }} R_{\text {jthp }}, R_{\text {jthsi }}(j=1, \ldots 2$ ) are the respective equivalent thermal resistances of the four first and four last nodes in the respective layers: conductor (copper), insulating (silica), core (permalloy) and substrate (silicon).

$C_{1-2}, C_{2-3}, C_{3-4}$ and $C_{1-2}^{\prime}, C_{2-3}^{\prime}, C_{3-4}^{\prime}$ are the respective equivalent thermal capacities of the four first and four last nodes in the three respective interfaces: copper-insulating, insulating-core and coresubstrate.

\section{TEMPERATURE CALCULATION PROCEDURE}

To calculate the operating temperatures in the different layers of the inductor, we consider the algorithm of figure 10. This algorithm summarizes the different steps. 


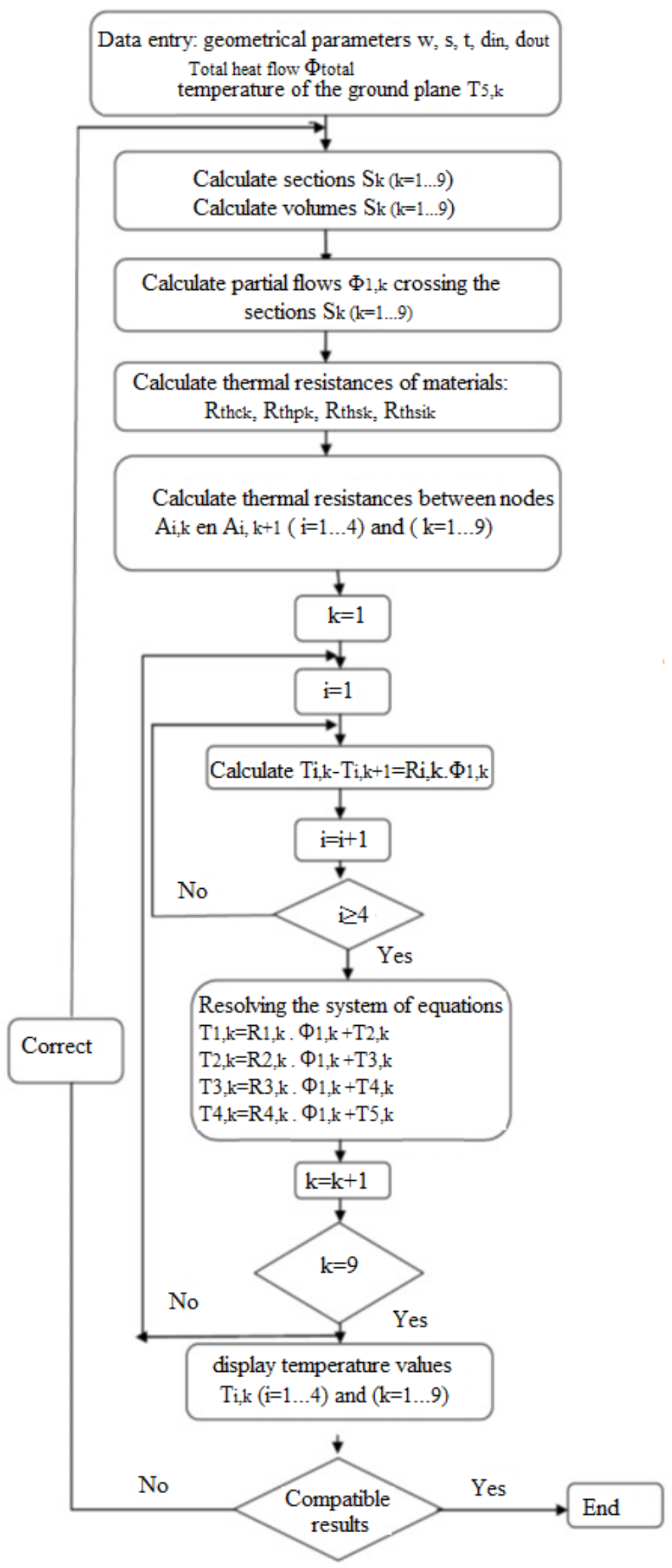

Figure 10. Procedure for calculating the temperatures in the different inductor layers 


\subsection{Thermal resistances calculation}

By analogy between the physical laws of thermal conduction and electric conduction, the thermal resistances are expressed by equation (1) [13] [14].

$$
R_{t h}=\frac{d}{\lambda_{t h} \cdot S_{k}}
$$

$d:$ is the distance between the node and the interface.

$\lambda_{t h}$ : is the thermal conductivity of the material.

$S_{k}$ : is the section crossed perpendicularly by the thermal flow.

The conductive ribbon of the inductor is sectioned into volumes $V_{l, k}\left(k=1, \ldots 9\right.$, each volume $V_{l, k}$ is a heat source. The heat flow transferred from each volume $V_{l, k}$ to the layers stacked below, crosses perpendicularly the section $S_{k}$. The calculation of the thermal resistances is done after the calculation of the sections $S_{k}(k=1, \ldots 9)$ (Table II)

TABLE II

EQUATIONS AND VALUES OF SECTIONS $S_{k}$

\begin{tabular}{ccc}
\hline \hline Section $\boldsymbol{S}_{\boldsymbol{k}}(\boldsymbol{k}=\mathbf{1}, . .9)$ & Equations & Results $\left(\boldsymbol{\mu \mathbf { m } ^ { 2 }}\right)$ \\
\hline \hline $\boldsymbol{S}_{1}$ & $S_{1}=\left(\frac{d_{i n}}{2}+2 w+s\right) \cdot w$ & 54000 \\
$\boldsymbol{S}_{2}$ & $S_{2}=\left(d_{i n}+3 w+3 s\right) \cdot w$ & 105300 \\
$\boldsymbol{S}_{3}$ & $S_{3}=\left(d_{i n}+4 w+2 s\right) \cdot w$ & 108000 \\
$\boldsymbol{S}_{4}$ & $S_{4}=\left(d_{i n}+2 w+2 s\right) \cdot w$ & 97200 \\
$S_{5}$ & $S_{5}=\left(d_{i n}+3 w+s\right) \cdot w$ & 81900 \\
$S_{6}$ & $S_{6}=\left(d_{i n}+w+s\right) \cdot w$ & 53100 \\
$S_{7}$ & $S_{7}=\left(d_{i n}+2 w\right) \cdot w$ & 55800 \\
$S_{8}$ & $S_{8}=d_{i n} \cdot w$ & 27000 \\
$S_{9}$ & $S_{9}=\left(\frac{d_{i n}}{2}+w\right) \cdot w$ & 27900 \\
\hline
\end{tabular}

\subsubsection{The thermal resistances of different materials}

The thermal resistances of the different stacked materials: copper $(\mathrm{Cu})$, silica $(\mathrm{SiO} 2)$, permalloy ( $\mathrm{NiFe)}$ and silicon substrate ( $\mathrm{Si})$ are respectively $R_{t h c k}, R_{t h o x k}, R_{t h p k}, R_{t h s i k}$.

The respective thermal conductivities values of the stacked materials are:

$\lambda_{c u}=349 \mathrm{Wm}^{-1} \mathrm{~K}^{-1}, \lambda_{o x}=1,46 \mathrm{Wm}^{-1} \mathrm{~K}^{-1}, \lambda_{\text {mag }}=30 \mathrm{Wm}^{-1} \mathrm{~K}^{-1}, \lambda_{\text {sub }}=149 \mathrm{Wm}^{-1} \mathrm{~K}^{-1}$

The calculation of the thermal resistances is done using equations (2).

$$
R_{t h c_{k}}=\frac{d_{c u}}{S_{k} \cdot \lambda_{c u}}, R_{\text {thox }_{k}}=\frac{t_{o x}}{S_{k} \cdot \lambda_{o x}}, R_{t h p_{k}}=\frac{h_{\text {mag }}}{S_{k} \cdot \lambda_{\text {mag }}}, R_{\text {thsi } i_{k}}=\frac{h_{\text {sub }}}{S_{k} \cdot \lambda_{\text {sub }}}
$$


$d_{c u}$ : Is the distance between the node of volume $V_{l, k}$ and the silica-copper interface $\left(d_{c u}=10 \mu m\right)$. $t_{o x}, h_{m a g}$ and $h_{s u b}$ Are the respective thicknesses of the different stacked materials (silica, permalloy and silicon), their values are respectively $t_{o x}=60 \mu \mathrm{m}, h_{m a g}=340 \mu \mathrm{m}$ and $h_{s u b}=100 \mu \mathrm{m}$.

Table III contains the calculated values of the thermal resistances of different materials in each volume $V_{i, k}(i=1, \ldots 4 ; k=1, \ldots 9)$.

TABLE III

THERMAL RESISTANCES OF DIFFERENT STACKED MATERIALS

\begin{tabular}{cccc}
\hline \hline $\mathbf{R}_{\text {thc }_{k}}(K / W)$ & $\mathbf{R}_{\text {thp }_{k}}(K / W)$ & $\mathbf{R}_{\text {ths }_{k}}(K / W)$ & $\mathbf{R}_{\text {thsi }_{k}}(K / W)$ \\
\hline \hline 0.476 & 209.88 & 761.03 & 12.43 \\
0.244 & 107.63 & 390.27 & 6.37 \\
0.238 & 104.95 & 380.52 & 6.21 \\
0.264 & 116.60 & 422.79 & 6.90 \\
0.314 & 138.38 & 501.78 & 8,19 \\
0.484 & 213.43 & 773.93 & 12.64 \\
0.461 & 203.11 & 736.48 & 12.03 \\
0.952 & 419.75 & 1522.20 & 24.86 \\
0.921 & 406.21 & 1472.97 & 24.06 \\
\hline
\end{tabular}

\section{CALCULATION OF THE INDUCTOR OPERATING TEMPERATURE}

The calculation of the temperatures in the different volumes $V_{i, k}(i=1, \ldots 4 ; k=1, \ldots 9)$ of the inductor (Figure 11) is done with the use of Fourier's law given by equation (3).

$$
R_{t h}=\frac{\Delta T}{\Phi}=\frac{T_{i}-T_{j}}{\Phi}
$$

$T_{i}$ and $T_{j}$ are the temperatures of two isotherms, $\Phi$ is the flow of heat between the two isotherms expressed in Watts. By applying the Fourier's law to Figure 11, we obtain equation (4).

$$
R_{i, k}=\frac{T_{i, k}-T_{i+1, k}}{\Phi_{1, k}}
$$

$R_{i, k}(i=1, \ldots 4 ; k=1, \ldots 9)$ are the thermal resistances between two nodes $A_{i, k}$ and $A_{i+1, k}$ $\Phi_{1, k}(k=1, \ldots 9)$ are the Partial thermal flows in the volumes $V_{l, k}(k=1, \ldots 9)$.

To calculate temperatures $T_{i, k}$ in each volume $V_{i, k}(i=1, \ldots 4 ; k=1, \ldots 9)$, it is first necessary to calculate the resistances $R_{i, k}$ and the Partial thermal flows $\Phi_{1, k}$.

The thermal flows $\Phi_{1, k}$ derive from the overall thermal flow $\Phi_{\text {total }}$. 


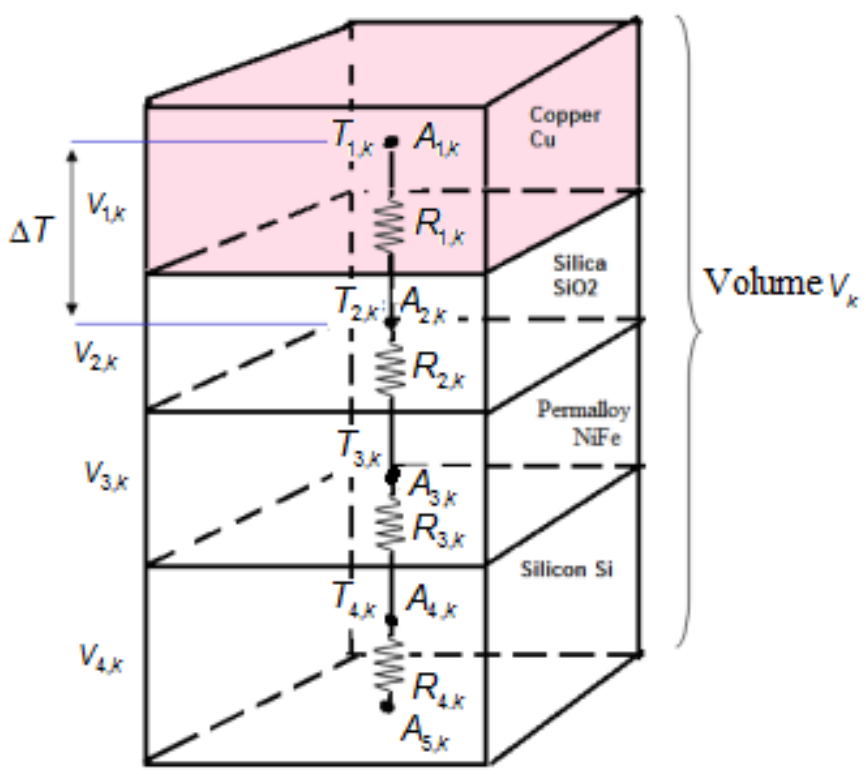

Figure 11. The different thermal resistances and different temperatures in a volume element $V_{k}$

\subsection{Calculation of the overall thermal flow}

The overall thermal flow $\Phi_{\text {total }}$ due to losses by Joule effect is assumed uniform throughout the conductor. This thermal flow represents the power dissipated by the conductive ribbon (equation $5)$.

$$
\Phi_{\text {total }}=\mathrm{P}=\mathrm{R}_{\mathrm{S}} \cdot\left(\mathrm{I}_{\text {Leff }}\right)^{2}
$$

$R_{S}$ is the ohmic resistance of the conductive ribbon given by equation (6)

$$
\mathrm{R}_{\mathrm{S}}=\rho_{c u} \frac{L_{\text {avg }}}{w \cdot t}
$$

$\rho_{c u}$ is the resistivity of copper $\rho_{c u}=1.710^{-8} \Omega \mathrm{m}$

With $I_{\text {Leff }}=0.4 A$ and $R_{S}=0.0311 \Omega$ we obtain:

$$
\Phi_{\text {total }}=4,976 \cdot 10^{-3} \mathrm{~W} .
$$

\subsection{Calculation of partial thermal flows}

The conductive ribbon of the inductor is discretized into nine volumes $V_{i, k}(i=1, \ldots 4 ; k=1, \ldots 9)$, their temperatures $T_{1, k}(k=1, \ldots 9)$ are assumed isothermal, the power dissipated by each volume $V_{l, k}(k=1, \ldots 9)$ represents a partial thermal flow $\Phi_{1, k}(k=1, \ldots 9)$. The partial thermal flows derive from the overall thermal flow $\Phi_{\text {total }}$ (expression 7).

$$
\Phi_{1, k}=\frac{V_{1, k}}{V_{g}} \Phi_{\text {total }}
$$

$V_{g}$ is the overall volume of the conductive ribbon.

Table IV shows the values of different thermal flows $\Phi_{1, k}(k=1, \ldots 9)$ in volumes $V_{l, k}(k=1, \ldots 9)$. 
TABLE IV

VALUES OF OVERALL AND PARTIAL THERMAL FLOWS IN THE VOLUMES $\boldsymbol{v}_{1, k}$

\begin{tabular}{|c|c|c|c|}
\hline \begin{tabular}{c}
\multicolumn{2}{c}{ Volumes } \\
$V_{g} \quad$ and $V_{1, k}$
\end{tabular} & $\begin{array}{c}\text { Values of volumes } \\
\qquad V_{1, \mathrm{k}}\left(\mu \mathrm{m}^{3}\right) \\
\end{array}$ & Thermal flows & $\begin{array}{l}\text { Values of thermal } \\
\text { flows } \Phi_{1, \mathrm{k}}(\mathrm{W})\end{array}$ \\
\hline $\begin{array}{l}\text { Averall volume } \\
\mathrm{V}_{\mathrm{g}}=L_{\text {avg }} . t . w\end{array}$ & $10566.10^{3}$ & $\Phi_{\text {total }}$ & $4.976 .10^{-3}$ \\
\hline$V_{1,1}$ & $108.10^{-4}$ & $\Phi_{1,1}$ & $0.5088 .10^{-3}$ \\
\hline$V_{1,2}$ & $2106.10^{-3}$ & $\Phi_{1,2}$ & $0.9916 .10^{-3}$ \\
\hline$V_{1,3}$ & $216.10^{-3}$ & $\Phi_{1,3}$ & $1.0172 .10^{-3}$ \\
\hline$V_{1,4}$ & $1944.10^{-3}$ & $\Phi_{1,4}$ & $0.9156 .10^{-3}$ \\
\hline$V_{1,5}$ & $1638.10^{-3}$ & $\Phi_{1,5}$ & $0.7712 .10^{-3}$ \\
\hline$V_{1,6}$ & $1062.10^{-3}$ & $\Phi_{1,6}$ & $0.5 .10^{-3}$ \\
\hline$V_{1,7}$ & 1116. $.10^{-3}$ & $\Phi_{1,7}$ & $0.5256 .10^{-3}$ \\
\hline$V_{1,8}$ & $54.10^{-3}$ & $\Phi_{1,8}$ & $0.2544 .10^{-3}$ \\
\hline$V_{1,9}$ & $558.10^{-3}$ & $\Phi_{1,9}$ & $0.2628 .10^{-3}$ \\
\hline
\end{tabular}

\subsection{Calculation of thermal resistances between nodes $A_{i, k}$ and $A_{i+1, k}$}

Figure 12 is deduced from figure 11.

In figure $12, R_{i, k}(i=1, \ldots 4 ; k=1, \ldots 9)$ are the thermal resistances between the nodes $A_{i, k}$ and $A_{i+1, k}$. $A_{i, k}(i=1, \ldots 4 ; k=1, \ldots 9)$ are the centers of gravity of volumes $V_{i, k}(i=1, \ldots 4 ; k=1, \ldots 9)$ (Figure 11), and resistances $R_{i, k}(i=1, \ldots 4 ; k=1, \ldots 9)$ are the elements of a matrix (Figure 12).

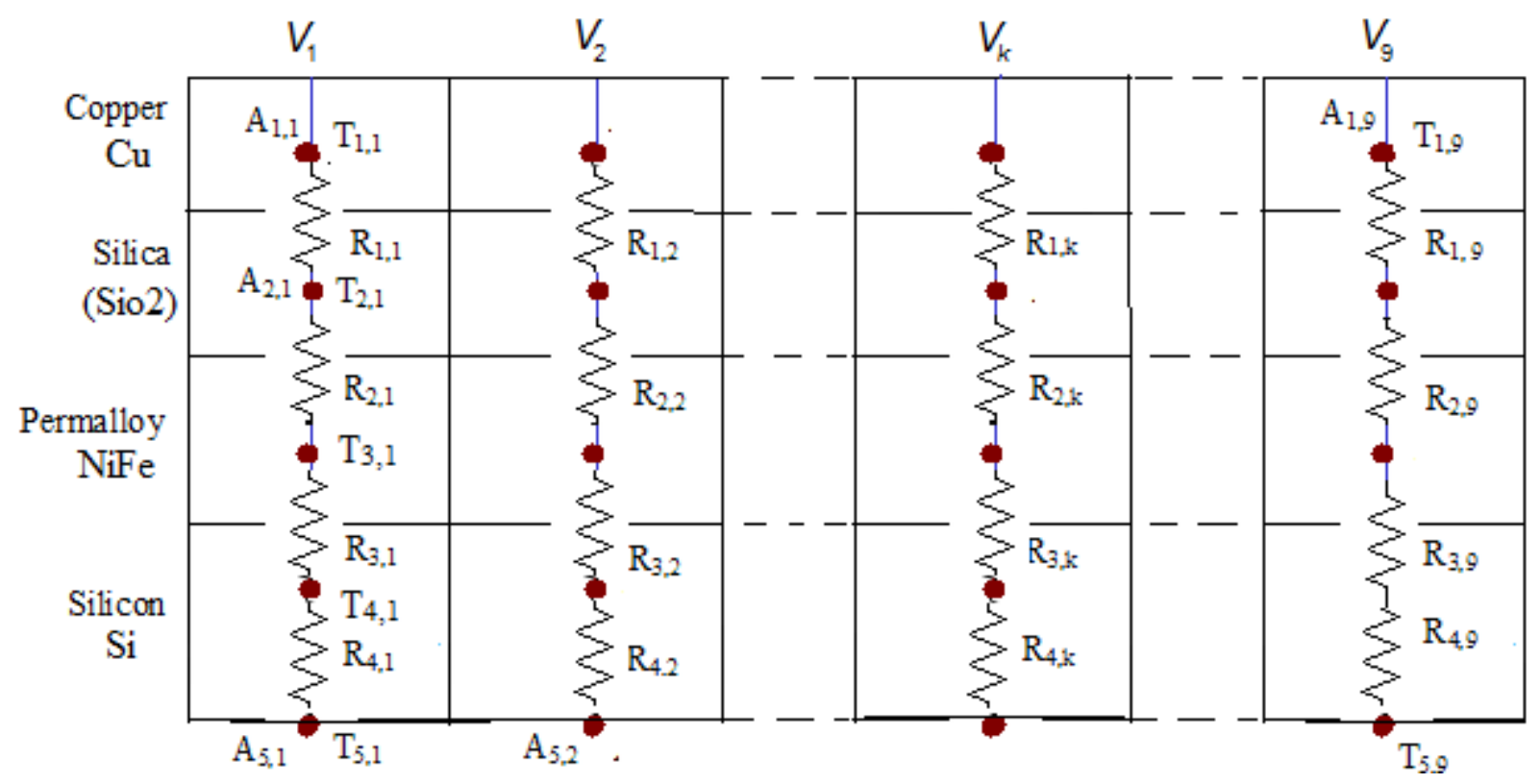

Figure 12. Different thermal resistances 
The calculation of the thermal resistances is done using the expressions (6).

$$
R_{1, k}=R_{\text {thc }_{k}}+\frac{\mathrm{R}_{\text {ths }_{\mathrm{k}}}}{2}, \quad R_{2, k}=\frac{R_{\text {ths }_{k}}+R_{\text {thp }_{\mathrm{k}}}}{2}, \quad R_{3, k}=\frac{R_{\text {thp }_{\mathrm{k}}}+R_{\text {thsi }_{k}}}{2} \quad R_{4, k}=\frac{\mathrm{R}_{\text {thsi }_{\mathrm{k}}}}{2}
$$

The matrix of resistances $R_{i, k}(i=1, \ldots 4 ; k=1, \ldots 9)$ in table $\mathrm{V}$ derived from figure 12 .

TABLE V

MATRIX OF THERMAL RESISTANCES $R_{i, k}(i=1, \ldots 4 ; k=1, \ldots 9)$.

$$
\left[\begin{array}{lllllllll}
R_{1,1} & R_{1,2} & R_{1,3} & R_{1,4} & R_{1,5} & R_{1,6} & R_{1,7} & R_{1,8} & R_{1,9} \\
R_{2,1} & R_{2,2} & R_{2,3} & R_{2,4} & R_{2,5} & R_{2,6} & R_{2,7} & R_{2,8} & R_{2,9} \\
R_{3,1} & R_{3,2} & R_{3,3} & R_{3,4} & R_{3,5} & R_{3,6} & R_{3,7} & R_{3,8} & R_{3,9} \\
R_{4,1} & R_{4,2} & R_{4,3} & R_{4,4} & R_{4,5} & R_{4,6} & R_{4,7} & R_{4,8} & R_{4,9}
\end{array}\right]
$$

Table VI shows the calculated values of the different thermal resistances $R_{i, k}(i=1, \ldots 4 ; k=1, \ldots 9)$.

TABLE VI

$$
\text { VALUES OF THERMAL RESISTANCES } R_{i, k}(i=1, \ldots 4 ; k=1, \ldots 9)
$$

$\left[\begin{array}{ccccccccc}380,99 & 195,38 & 190,50 & 211,66 & 251,20 & 387,45 & 368,70 & 762,05 & 737,41 \\ 485,46 & 248,95 & 242,74 & 269,70 & 320,08 & 493,68 & 469,80 & 970,98 & 939,59 \\ 111,16 & 57,00 & 55,58 & 61,75 & 73,29 & 113,06 & 107,57 & 222,31 & 215,16 \\ 06,22 & 03,19 & 03,11 & 03,45 & 04,10 & 06,32 & 06,02 & 12,43 & 12,03\end{array}\right]$

\subsection{Calculation of the operating temperatures of the inductor}

To calculate the operating temperature $T_{i, k}$ at each node $A_{i, k}$, we use expression 8 .

$$
R_{i, k}=\frac{\Delta T}{\Phi}=\frac{T_{i, k}-T_{i+1, k}}{\Phi_{1, k}} \Rightarrow T_{i, k}-T_{i+1, k}=R_{i, k} \cdot \Phi_{1, k}
$$

By setting $\mathrm{k}$ and varying $\mathrm{i}$ from 1 to 4 in expression (8), we obtain the equations system (9).

$$
\left\{\begin{array} { l } 
{ T _ { 1 , k } - T _ { 2 , k } = R _ { 1 , k } \cdot \Phi _ { 1 , k } } \\
{ T _ { 2 , k } - T _ { 3 , k } = R _ { 2 , k } \cdot \Phi _ { 1 , k } } \\
{ T _ { 3 , k } - T _ { 4 , k } = R _ { 3 , k } \cdot \Phi _ { 1 , k } } \\
{ T _ { 4 , k } - T _ { 5 , k } = R _ { 4 , k } \cdot \Phi _ { 1 , k } }
\end{array} \Rightarrow \left\{\begin{array}{l}
T_{1, k}=R_{1, k} \cdot \Phi_{1, k}+T_{2, k} \\
T_{2, k}=R_{2, k} \cdot \Phi_{1, k}+T_{3, k} \\
T_{3, k}=R_{3, k} \cdot \Phi_{1, k}+T_{4, k} \\
T_{4, k}=R_{4, k} \cdot \Phi_{1, k}+T_{5, k}
\end{array}\right.\right.
$$

With $\mathrm{k}$ varying from 1 to 9 , we obtain nine similar equations systems.

We assume that the ground plane is at ambient temperature $\left(20{ }^{\circ} \mathrm{C}\right)$, therefore $T_{5, k}=20^{\circ} \mathrm{C}$ for $(i=1, \ldots 4)$, and we solve the equations system (9).

The results are given in table VII for $(k=1, \ldots 9)$. 
TABLE VII

OPERATING TEMPERATURES IN DIFFERENT AREAS OF THE INDUCTOR

\begin{tabular}{|c|c|c|c|c|c|c|c|c|c|}
\hline $\mathrm{T}_{\mathrm{Cu}} \rightarrow$ & 20,504 & 20,503 & 20,504 & 20,503 & 20,504 & 20,504 & 20,504 & 20,504 & 20,504 \\
\hline $\mathrm{T}_{\mathrm{SiO} 2} \rightarrow$ & 20,31 & 20,31 & 20,31 & 20,31 & 20,31 & 20,31 & 20,31 & 20,31 & 20,31 \\
\hline $\mathrm{viFe} \rightarrow$ & 20,06 & 20,06 & 20,06 & 20,06 & 20,06 & 20,06 & 20,06 & 20,06 & 20,06 \\
\hline & 20,003 & 20,003 & 20,003 & 20,003 & 20,003 & 20,003 & 20,003 & 20,003 & 20,003 \\
\hline
\end{tabular}

\subsection{Results interpretation}

Since the operating temperature of the electronic power devices is between $20^{\circ} \mathrm{C}$ and $120^{\circ} \mathrm{C}$ [9], we conclude that the results in Table VII are good.

The temperature of the permalloy layer $(\mathrm{NiFe})$ is $20.06^{\circ} \mathrm{C}$, so there is no risk of demagnetization of the core because the Curie temperature of the permalloy $\left(600^{\circ} \mathrm{C}\right.$.) is far from being reached.

We note also that the temperature of the silicon layer is uniformly distributed and is not high, therefore, there is no risk of increasing the intrinsic conductibility of the semiconductor and of the conductivity of the substrate.

To see the heat distribution in the conductive ribbon of the inductor during its operating, a simulation of the temperature was performed with the FEMLAB 3.1 software (Figure 13-14-15).

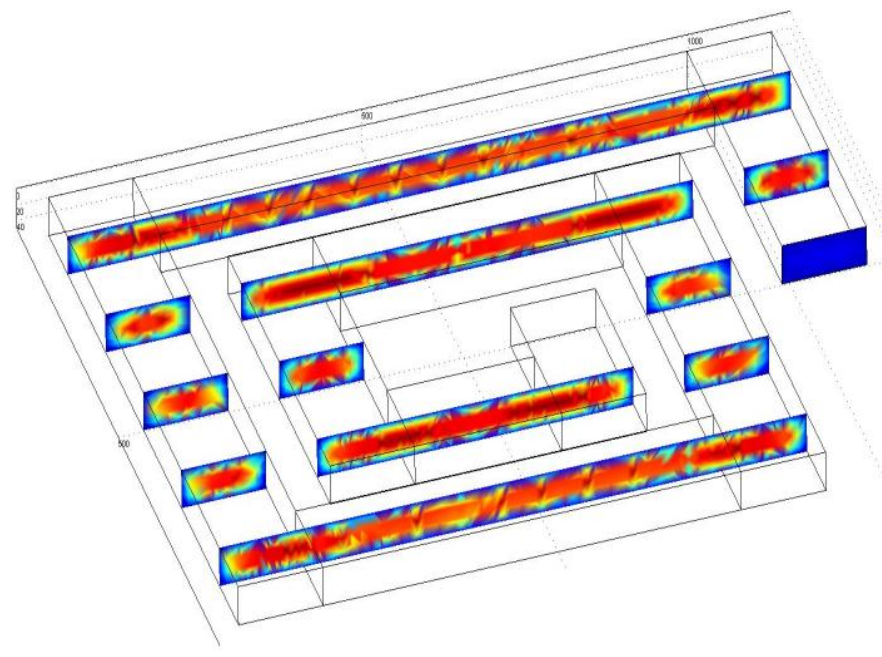

Figure 13. Simulation of the thermal flow in the inductor before its dissipation

The thermal flow is uniformly distributed along the conductive ribbon. Figure 13 shows no skin effect, no proximity effect. We conclude therefore, it has no risk of overheating the conductive ribbon.

In order to simulate the heat transfer, we place the conductive tape on the insulating layer and make cross-sections of these two layers ( figure 14 and figure 15). 


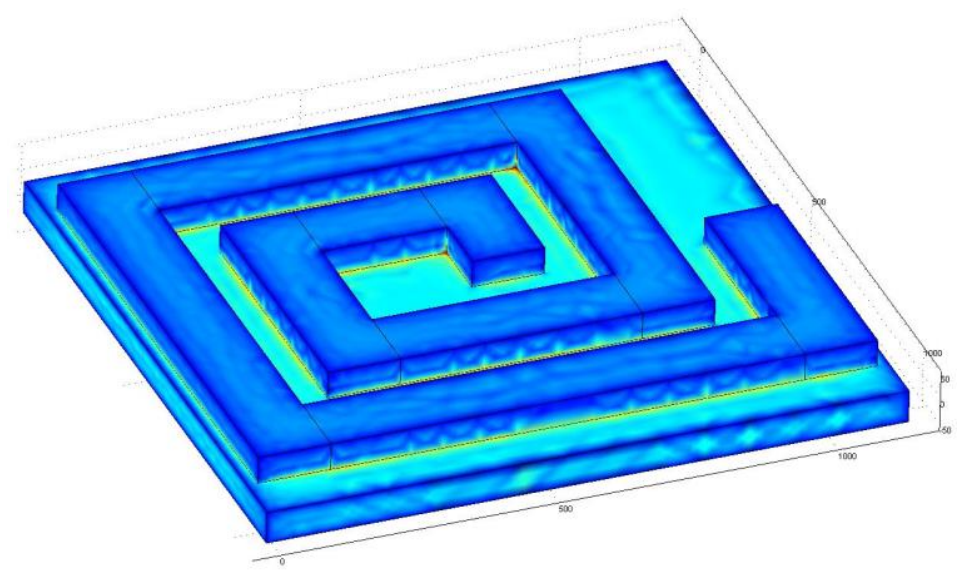

Figure 14. Conductive ribbon laid on the insulating layer

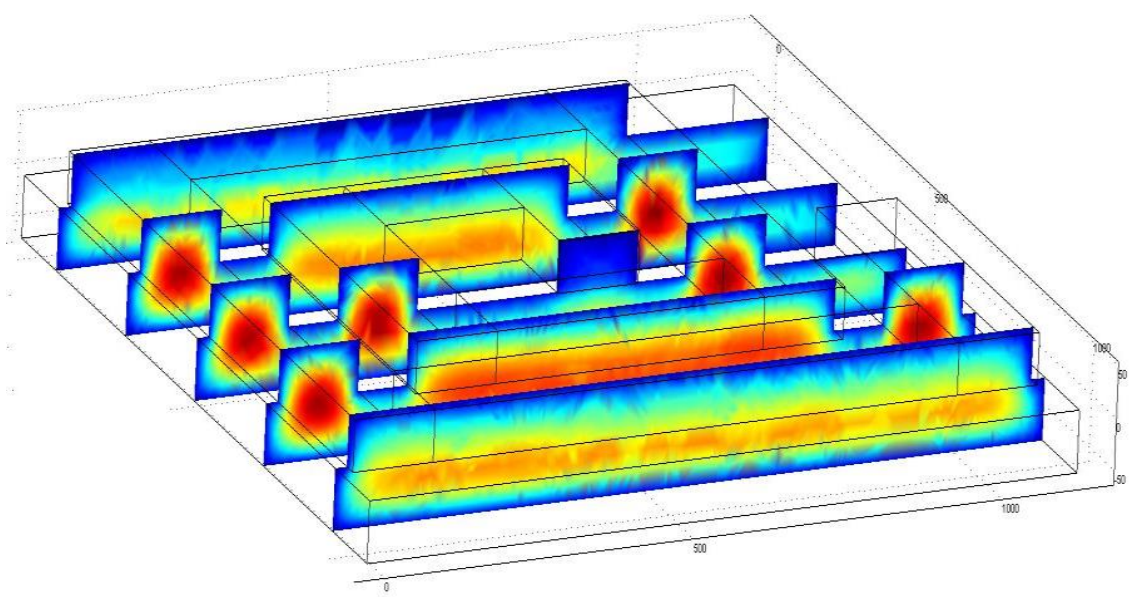

Figure 15. Transfer of the thermal flow from the conductive ribbon toward the insulating layer

Figure 15 shows the heat transfer along the conductive ribbon.

During the operation of the inductor, the heat does not stagnate in the conductive ribbon, but it is transferred to the stacked layers bellow to be evacuated outwardly through the silicon layer.

\section{CONCLUSION}

The integrated inductor is a fundamental element in a micro-converter, therefore the study of the thermal behavior of the inductor is very important.

To describe the thermal behavior of the inductor and calculate its operating temperature, we proposed a simple approach. This approach is based on the design of the inductor's thermal circuit. The nodal method, the cross section of the inductance and the similarity between the thermal and electrical circuits, facilitated the design of a " $\pi$ " thermal circuit of the inductor.

Fourier's law and the established thermal circuit, allowed us to determine the operating temperatures in different areas of the inductor. The calculated temperatures are good, so, the results are encouraging.

We validate this work using the FEMLAB 3.1 software. The image provided from the simulation shows no skin effect and no proximity effect, therefore, the operating temperature are uniform and there is no risk of overheating of the conductive ribbon or the inductor. 
Heat does not stagnate in the conductive ribbon, but it is transferred to the stacked layers below, to be evacuated to the external environment through the silicon substrate which is a good heat conductor.

We conclude so, that the approach presented in this paper is reliable, simple and very easy to applied, compared to other methods such as the finite element method and the finite difference method.

\section{REFERENCES}

[1] K. Sun, Z. Lan, and all, “ Temperature dependence of core losses at high frequency for MnZn ferrites”. Physica B Condensed Matter Vol, 405, №3, February (2010), pp. 10181021.

[2] I. Papagiannopoulos, V. Chatziathanasiou and all, "Thermal analysis of integrated spiral inductors", Infrared Physics \& Technology Volume 56 (January 2013), pp. 80-84.

[3] Y. Benhadda, A. Hamid, T. Lebey and all, " Thermal Behavior of an Integrated Square Spiral Micro Coil” TELKOMNIKA Indonesian Journal of Electrical Engineering, Vol, 14, $\mathrm{N}^{\circ}$. 2, May (2015), pp. 250-265.

[4] P Viarouge, JC Fagundes, E Tourkhani, H Le-Huy. “ Comportement Thermique et Conception des Composants Magnétiques dans les Convertisseurs Statiques de Fréquence Elevée”. IEEE. (1995), pp. 582-585.

[5] M. Arab, E. Laboure and F. Costa, "Design of an integrated inductor-transformer LT component for power electronic applications", Power Electronics Specialists Conference (2004). PESC 04. 2004 IEEE 35th Annual, Vol. 6, pp. 4861-4866.

[6] L. Seung-Yo, W.G. Odendaal and J.D. van Wyk, "Thermo-mechanical stress analysis for an integrated passive resonant module", Industry Applications Conference (2002). 37th IAS Annual Meeting. Conference Record of the, Vol. 3, pp. 1752-1757.

[7] R Melati., A. Hamid, T. Lebey, "Design of a new electrical model of a ferromagnetic planar inductor for its integration in a micro-converter", Mathematical and Computer Modelling, (January 2013), Vol. 57, N¹-2, pp. 200-227.

[8] A. Allaoui, A. Hamid, Spiteri, P and all, "Thermal Modeling of an Integrated Inductor in a Micro-Converter", Journal of Low Power Electronics (2015), Vol. 11, № 1, pp. 63-73.

[9] M.T. Abakar, “ Modélisation thermique des composants magnétiques utilisés en électronique de puissance », Doctoral Thesis, National Institute of Applied Sciences of Lyon (2003).

[10] K. Lai Dac, “Contribution à l'optimisation du dimensionnement de composants passifs intégrés pour l'électronique de puissance", Doctoral Thesis, University of Grenoble (2010).

[11] J-P. Petit “Dissipation thermiques dans les systèmes électroniques", Technique de l'Ingénieur Edition (2012).

[12] A. Fasquelle, "Contribution à la modélisation multi-physique : électro-vibro-acoustique et aérothermique de machines de traction", Doctoral Thesis, Central School of Lille (November 2007).

[13] J-M. Dorkel, "Semi-conducteurs de puissance - Problèmes thermiques" (part 1), Technique de l'Ingénieur Edition (2012). 
[14] P. Tounsi, "Methodologie de la conception thermique des circuits électroniques hybrides et problèmes connexes “, Doctoral Thesis, Polytechnic National Scool, (December 1992). 